\title{
Natural deep eutectic solvents as new potential media for green technology
}

\author{
Yuntao Dai ${ }^{\mathrm{a}}$, Jaap van Spronsen ${ }^{\mathrm{b}}$, Geert-Jan Witkamp ${ }^{\mathrm{b}}$, \\ Robert Verpoorte $^{\mathrm{a}}$, Young Hae Choi ${ }^{\mathrm{a}, *}$ \\ a Natural Products Laboratory, Institute of Biology, Leiden University, 2300 RA Leiden, The Netherlands \\ ${ }^{\mathrm{b}}$ Laboratory for Process Equipment, Delft University of Technology, Delft, The Netherlands
}

\section{H I G H L I G H T S}

- Natural products were used as a source for deep eutectic solvents and ionic liquids.

- We define own chemical and physical properties of natural deep eutectic solvents.

- Interaction between natural deep eutectic solvents and solutes was confirmed by NMR.

- The developed natural deep eutectic solvents were applied as green media.

\section{A R T I C L E I N F O}

\section{Article history:}

Received 30 October 2012

Received in revised form

12 December 2012

Accepted 13 December 2012

Available online 9 January 2013

\section{Keywords:}

Natural deep eutectic solvents

Ionic liquids

Physicochemical properties

Green technology

Solubility

\section{G R A P H I C A L A B S T R A C T}

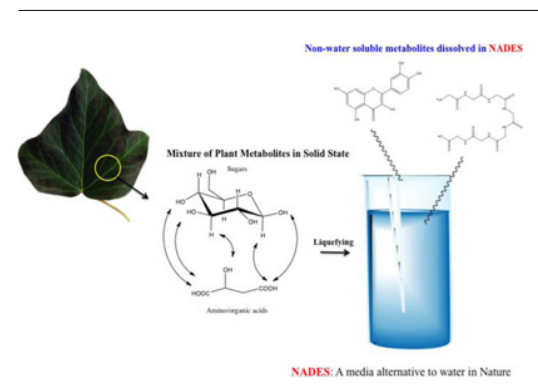

\begin{abstract}
A B S T R A C T
Developing new green solvents is one of the key subjects in Green Chemistry. Ionic liquids (ILs) and deep eutectic solvents, thus, have been paid great attention to replace current harsh organic solvents and have been applied to many chemical processing such as extraction and synthesis. However, current ionic liquids and deep eutectic solvents have still limitations to be applied to a real chemical industry due to toxicity against human and environment and high cost of ILs and solid state of most deep eutectic solvents at room temperature. Recently we discovered that many plant abundant primary metabolites changed their state from solid to liquid when they were mixed in proper ratio. This finding made us hypothesize that natural deep eutectic solvents (NADES) play a role as alternative media to water in living organisms and tested a wide range of natural products, which resulted in discovery of over 100 NADES from nature. In order to prove deep eutectic feature the interaction between the molecules was investigated by nuclear magnetic resonance spectroscopy. All the tested NADES show clear hydrogen bonding between components. As next step physical properties of NADES such as water activity, density, viscosity, polarity and thermal properties were measured as well as the effect of water on the physical properties. In the last stage the novel NADES were applied to the solubilization of wide range of biomolecules such as non-water soluble bioactive natural products, gluten, starch, and DNA. In most cases the solubility of the biomolecules evaluated in this study was greatly higher than water. Based on the results the novel NADES may be expected as potential green solvents at room temperature in diverse fields of chemistry.
\end{abstract} (C) 2012 Elsevier B.V. All rights reserved.

\footnotetext{
* Corresponding author. Tel.: +31 71527 4510; fax: +31 715274510

E-mail address: y.choi@chem.leidenuniv.nl (Y.H. Choi).
}

\section{Introduction}

Currently green technology is one of the key issues in chemistry fields because it aims to preserve environment and to reduce the negative influence of human involvement. The green technology 
facilitates the minimum use of non-hazardous media, new environmentally acceptable solubilization techniques by controlling physical properties of media such as temperature and pressure, and developing new green solvents. Of the diverse ways of green technology developing new green solvents may be the most important subjects. In the context ionic liquids and deep eutectic solvents have been paid great attention to replace current harsh organic solvents.

It is a well-known phenomenon that pure solid chemicals can become liquid by mixing in certain ratios as in the case of ionic liquids and deep eutectic solvents. Ionic liquids (ILs) are a class of organic salts with a low melting point. Recently, with the aim of developing environmentally friendly solvents, ILs have received increasing attention because they have a negligible vapor pressure and can be tailored concerning polarity and selectivity for different applications such as chemical or enzymatic reactions $[1,2]$. Another type of solvent with similar physical properties and phase behavior to ILs are deep eutectic solvents (DES) [3]. These solvents are mixtures of compounds that have a much lower melting point than that of any of its individual components, mainly due to the generation of intermolecular hydrogen bonds. The principle of creating ILs and DES was demonstrated for mixtures of quaternary ammonium salts [4] with a range of amides and carboxylic acids [5], and later extended to choline chloride with alcohols [6], and urea with sugars or organic acids $[7,8]$. Some features of these DES make that they have an advantage over ILs because they are easier to prepare with high purity at low cost. Higher melting points of many DES, however, can hamper their application as a green solvent at room temperature. Compared to the broad applications of ILs [9-12], the application of DES has been so far limited to organic reactions $[7,8,13]$, organic extractions [14], electrochemistry [15-17], and enzyme reactions carried out at $60^{\circ} \mathrm{C}$ [6]. Moreover, the synthetic ILs suffer from high toxicity of some of the ingredients $[18,19]$, which is hampering their use in pharmaceutical and food related products.

In order to increase the number of candidates for ILs and DES and extend their applications, apart from synthetic compounds, attention has directed towards natural products such as organic acids [5,8,20], amino acids [21], sugars [7,22], choline [4,6], or urea $[4,7,8]$. Natural products are indeed a plentiful and ideal source of ILs and DES due to their enormous chemical diversity, biodegradable properties and pharmaceutically acceptable toxicity profile. There is, however, an even more interesting aspect. We recently postulated that in living organisms there is an alternative medium to water and lipids, because if they were the only two media it would be difficult to explain a great number of biological processes that occur in all organisms, such as biosynthesis of poorly water soluble metabolites and macromolecules in the aqueous environment of cells, also survival of organisms in extreme drought (e.g. cacti, resurrection plants, lichen, prokaryotes), and/or cold conditions (e.g. seeds, prokaryotes). The occurrence of ILs and DES in living organisms can explain many of these biological phenomena [14]. This hypothesis was based on the observation that many potential ingredients of ILs and DES are always observed in large and about similar amounts in NMR-based metabolomics of all type of cells and organisms.

To prove our recently published hypothesis [23] that ILs and DES might play an important role as a liquid phase for solubilizing, storing, and transporting non-water soluble metabolites in living cells and organisms, we tested different mixtures of various abundant cellular constituents (primary metabolites) to make liquid, measure their important physicochemical properties, and test their solubilization ability for poorly water soluble metabolites and also macromolecules. Furthermore, the existence of NADES in plants was also explored.

\section{Materials and methods}

\subsection{NADES preparation}

Two methods were used for preparing natural deep eutectic solvents (NADES): a vacuum evaporating and a heating method. Evaporating method: components were dissolved in water and evaporated at $50{ }^{\circ} \mathrm{C}$ with a rotatory evaporator. The liquid obtained was put in a desiccator with silica gel till they reached a constant weight. Heating method: this method was employed to obtain NADES with a known amount of water. The two-component mixture with calculated amounts of water was placed in a bottle with a stirring bar and cap and heated in a water bath below $50^{\circ} \mathrm{C}$ with agitation till a clear liquid was formed (about 30-90 min). The viscous liquids were tested on a ${ }^{1} \mathrm{H}$ NMR spectrometer at $40^{\circ} \mathrm{C}$.

\subsection{NMR spectroscopy}

NMR experiments: ${ }^{1} \mathrm{H}$ NMR spectra, 2D NOESY and HOESY spectra were recorded at 25 and $40^{\circ} \mathrm{C}$ on a Bruker $500 \mathrm{MHz}$ DMX NMR spectrometer ( $500.13 \mathrm{MHz}$ proton frequency) equipped with a $\mathrm{TCI}$ cryoprobe and $Z$-gradient system. For $1 \mathrm{D}-{ }^{1} \mathrm{H}$ NMR spectra, a total of 32768 data points were recorded covering a spectral window of $9615 \mathrm{~Hz} ; 128$ scans of a standard one-pulse sequence with $90^{\circ}$ flip angle for excitation and presaturation during 2.0 s relaxation delay. An exponential window function with a line-broadening factor of $0.3 \mathrm{~Hz}$ was applied prior to Fourier transformation. The resulting spectra were manually phased and baseline corrected. ${ }^{1} \mathrm{H}-{ }^{1} \mathrm{H}$ NOESY spectra were acquired with presaturation $\left(B_{1}=50 \mathrm{~Hz}\right)$ during a relaxation delay of $1.5 \mathrm{~s}$. A data matrix of $1024 \times 2048$ points covering $7739.4 \times 7739.4 \mathrm{~Hz}$ was recorded with 16 scans for each increment. Data were zero filled to $2048 \times 2048$ points prior to States-TPPI type 2D Fourier transformation and a sine bell-shaped window function was applied in both dimensions. Mixing time was $100 \mathrm{~ms}$. 2D NOESY spectra were recorded at $25^{\circ} \mathrm{C}$ on a Bruker $400 \mathrm{MHz}$ HR-MAS NMR spectrometer at frequence of $3000 \mathrm{~Hz}$ without buffer and $\mathrm{D}_{2} \mathrm{O}$.

\subsection{Physicochemical properties tests}

Thermogravimetric analysis (TGA) was performed using PerkinElmer TGA 7, heating from room temperature to $100^{\circ} \mathrm{C}$, kept at $100^{\circ} \mathrm{C}$ for $1 \mathrm{~h}$, and then up to $300^{\circ} \mathrm{C}$ at a rate of $10^{\circ} \mathrm{C} \mathrm{min}-1$ in air. Differential scanning calorimetry (DSC) curve was recorded using PerkinElmer Diamond DSC, from $-120^{\circ} \mathrm{C}$ to $50^{\circ} \mathrm{C}$ at a rate of $10^{\circ} \mathrm{Cmin}^{-1}$ with heat down and heat up process in nitrogen. Density tests were performed using a density meter (DMA 5000) at $40^{\circ} \mathrm{C}$. Viscosity test was performed using a viscometer 16983 , type $U$-tube reverse (P.M. Tamson B.V. Zoetermeer, The Netherlands) in a thermostatic bath TVB 445 (Labovisco B.V., The Netherlands) at $40^{\circ} \mathrm{C}$. Water activity test was performed in a water activity measurement equipment at $40^{\circ} \mathrm{C}$. Polarity testing was done with Nile red (NR) as a solvatochromatic probe. The $\lambda_{\max }$ was determined and used in the formula $E_{\mathrm{NR}}\left(\mathrm{kcal} \mathrm{mol}^{-1}\right)=h c \lambda_{\max } N_{\mathrm{A}}=28591 / \lambda_{\max }$ to obtain $E_{\mathrm{NR}}[24]$.

\subsection{Solubility tests}

Solubility tests were carried out by saturating NADES with an excess of the tested compound in a bottle with a cap, stirring at $40^{\circ} \mathrm{C}$ for $2 \mathrm{~h}$ and leaving to rest for $3 \mathrm{~h}$ for precipitation (centrifuging $20 \mathrm{~min}$ for DNA and gluten after dissolving for $2 \mathrm{~h}$ ). Triplicate samples of the resulting solution were diluted with water. The diluted solutions were analyzed with HPLC-UV at wavelength of $360 \mathrm{~nm}$ for rutin, $370 \mathrm{~nm}$ for quercetin, $272 \mathrm{~nm}$ for cinnamic acid, $517 \mathrm{~nm}$ for carthamin, $472 \mathrm{~nm}$ for 1,8-dihydroxyanthaquinone, and quantified 
with a UV/Vis spectrophotometer at $217 \mathrm{~nm}$ for ginkgolide $B$, $228 \mathrm{~nm}$ for taxol, $260 \mathrm{~nm}$ for DNA, and $595 \mathrm{~nm}$ for gluten with Bradford method. Solubility of starch was performed as follows: a known amount of starch was placed in a glass vial with a cap and $5 \mathrm{~mL}$ of NADES were added. The vial was vortexed, then loosely capped, placed in a microwave oven and repeatedly heated with 5-10 s pulses at full power till the liquid boiled. Between pulses, the vial was removed, and $1 / 10$ of the original amount of the sample was added, vortexed and replaced in the oven if fully soluble. If not soluble, the sample amount was reduced and the above steps were repeated till a cloudy solution became clear when boiled [25].

\section{Results and discussion}

Previously we discovered that many plant primary metabolites in solid state became liquid when they mixed in a certain condition [23]. We hypothesized that these liquids may play a role as alternative media to water in living organisms. To prove our recently published hypothesis that ILs and DES might play an important role as a liquid phase for solubilizing, storing, and transporting non-water soluble metabolites in living cells and organisms, we tested different mixtures of various abundant cellular constituents (primary metabolites) such as sugars, sugar alcohols, amino acids, organic acids, and choline derivatives. Indeed many combinations of these compounds were found to be liquids. We introduced the term Natural Deep Eutectic Solvents (NADES) for these liquids. The exploration of different combinations of these common metabolites abundantly present in all types of cells and organisms provided over 100 combinations of NADES (Table 1). Choline chloride, for example, in combination with any kind of primary metabolite, can make liquids. One may distinguish four main groups: ionic liquids with an acid and a base, sugar based NADES with only neutral compounds, sugar based NADES with bases and sugar based NADES with acids. Surprisingly, different kinds of sugars or organic acids mixtures can also form liquids, such as fructose-glucose-sucrose [23] and malic acid-citric acid. Other combinations of more than two components can also lead to clear liquids, such as glucose-sorbitol-malic acid or choline chloride-proline-malic acid. These multi-component mixtures might be closer to the NADES found in plants since plants have, naturally, a pool of all these metabolites.

\subsection{Discovery of NADES in nature}

Similar combinations are also observed in plants secretions, and plants in drought, or cold conditions. In fact, the ingredients for natural ILs and DES are abundant in organisms, which leads to our hypothesis that the natural ILs and DES play important physiological roles as a third medium polar liquid in living cells and organisms [23]. For example, the NMR spectrum of nectar of flowers, a liquid, shows that it is composed mainly of sugars which are individually in their solid form at room temperature; but the composition of the mixture of sugars in this secretion is a liquid similar to our proposed composition, a fructose-glucose-sucrose NADES [23], and the same applies for the components found in the honey, which is composed of glucose and fructose (Fig. S1-a). Components of NADES were also observed in desert plants of the Selaginela species, like Mexican moss, but also in microorganisms, lichen, and various other organisms that can survive longer periods without water, such as barley seeds with a high amount of sucrose and choline in episperm during dormancy (Fig. S1-b). Various investigations showed that the level of primary metabolites increases in the case of water shortage even for normal plants, such as Arabidopsis which shows increased levels of sugars (sucrose), amino acids (proline, alanine, arginine), organic acids (succinic acid, fumaric acid, malic acid) and
Table 1

Different combinations of natural ionic liquids or deep eutectic solvents from natural products made through vacuum evaporating method.

\begin{tabular}{|c|c|c|c|}
\hline \multicolumn{3}{|l|}{ Components } & \multirow[t]{2}{*}{ Mole ratio } \\
\hline Component 1 & Component 2 & Component 3 & \\
\hline Choline chloride & Lactic acid & & $1: 1$ \\
\hline Choline chloride & Malonic acid & & $1: 1$ \\
\hline Choline chloride & Maleic acid & & $1: 1,2: 1$ \\
\hline Choline chloride & DL-Malic acid & & $1: 1,1.5: 1$ \\
\hline Choline chloride & Citric acid & & $1: 1,2: 1$ \\
\hline Choline chloride & Aconitic acid & & $1: 1$ \\
\hline Choline chloride & $\mathrm{L}-(+)$-Tartaric acid & & $2: 1$ \\
\hline Choline chloride & Glycol & & $1: 1,1: 2$ \\
\hline Choline chloride & 1,2-Propanediol & & $1: 1,1: 1.5,1: 2,1: 3$ \\
\hline Choline chloride & 1,2-Propanediol & & $2: 1^{\mathrm{a}}$ \\
\hline Choline chloride & Glycerol & & $1: 1,3: 2$ \\
\hline Choline chloride & meso-Erythritol & & $2: 1^{\mathrm{a}}$ \\
\hline Choline chloride & Xylitol & & $5: 2$ \\
\hline Choline chloride & Adonitol & & $5: 2$ \\
\hline Choline chloride & Ribitol & & $5: 2$ \\
\hline Choline chloride & D-Sorbitol & & $3: 1,5: 2$ \\
\hline Choline chloride & D-Xylose & & $2: 1,3: 1$ \\
\hline Choline chloride & A-L-Rhamnose & & $2: 1$ \\
\hline Choline chloride & D-(+)-Glucose & & $1: 1,2: 1^{\mathrm{a}}$ \\
\hline Choline chloride & D-(+)-Glucose & & $5: 2$ \\
\hline Choline chloride & D-(-)-Fructose & & $1: 1,1: 1.5,1: 2^{\mathrm{a}}$ \\
\hline Choline chloride & D-(-)-Fructose & & $5: 2$ \\
\hline Choline chloride & Sorbose & & $5: 2,1: 1$ \\
\hline Choline chloride & D-Mannose & & $5: 2$ \\
\hline Choline chloride & D-(+)-Galactose & & $5: 2$ \\
\hline Choline chloride & Sucrose & & $4: 1,1: 1$ \\
\hline Choline chloride & D-(+)-Trehalose & & $4: 1$ \\
\hline Choline chloride & Maltose & & $4: 1$ \\
\hline Choline chloride & Raffinose & & $11: 2$ \\
\hline Choline chloride & Proline & DL-Malic acid & $1: 1: 1$ \\
\hline Choline chloride & Xylitol & DL-Malic acid & $1: 1: 1$ \\
\hline Choline bitartrate & D-(+)-Glucose & & $1: 1$ \\
\hline Betaine & D-(+)-Glucose & & $5: 2^{\mathrm{a}}$ \\
\hline Betaine & Sucrose & & $4: 1,1: 1^{\mathrm{a}}$ \\
\hline Betaine & Sucrose & & $2: 1$ \\
\hline Betaine & D-(+)-Trehalose & & $4: 1$ \\
\hline Betaine & D-Sorbitol & & $3: 1^{\mathrm{a}}$ \\
\hline Betaine & DL-Malic acid & & $1: 1$ \\
\hline Betaine & L-(+)-Tartaric acid & & $2: 1$ \\
\hline Betaine & D-Mannose & & $5: 2$ \\
\hline Betaine & Inositol & Raffinose & $9: 1: 1^{\mathrm{a}}$ \\
\hline Betaine & Sucrose & Proline & $1: 1: 1$ \\
\hline Betaine & Sucrose & Proline & $5: 2: 2$ \\
\hline Betaine & D-(+)-Glucose & Proline & $1: 1: 1$ \\
\hline Betaine & DL-Malic acid & D-(+)-Glucose & $1: 1: 1$ \\
\hline Betaine & DL-Malic acid & Proline & $1: 1: 1$ \\
\hline Betaine & DL-Malic acid & Inositol & $1: 1: 1^{\mathrm{a}}$ \\
\hline Betaine & Oxalic acid & D-(+)-Glucose & $1: 1: 1$ \\
\hline Betaine & Citric acid & & $1: 1$ \\
\hline Lactic acid & D-(+)-Glucose & & $5: 1$ \\
\hline Lactic acid & $\beta$-Alanine & & $1: 1$ \\
\hline DL-Malic acid & D-Xylose & & $1: 1^{\mathrm{a}}$ \\
\hline DL-Malic acid & D-(+)-Glucose & & $1: 1,1: 2^{\mathrm{a}}$ \\
\hline DL-Malic acid & Sucrose & & $1: 1$ \\
\hline DL-Malic acid & D-(-)-Fructose & & $1: 1^{\mathrm{a}}$ \\
\hline DL-Malic acid & D-Mannose & & $1: 1$ \\
\hline DL-Malic acid & Sucrose & & $1: 1,2: 1$ \\
\hline DL-Malic acid & Maltose & & $2: 1^{\mathrm{a}}$ \\
\hline DL-Malic acid & D-(+)-Trehalose & & $2: 1$ \\
\hline DL-Malic acid & Lactose & & $2: 1,1: 1$ \\
\hline DL-Malic acid & Raffinose & & $3: 1^{a}$ \\
\hline DL-Malic acid & Xylitol & & $1: 1^{\mathrm{a}}$ \\
\hline DL-Malic acid & Adonitol & & $1: 1^{\mathrm{a}}$ \\
\hline DL-Malic acid & D-Sorbitol & & $1: 1$ \\
\hline DL-Malic acid & D-(+)-Glucose & D-(-)-Fructose & $1: 1: 1$ \\
\hline DL-Malic acid & D-(+)-glucose & Glycerol & $1: 1: 1$ \\
\hline DL-Malic acid & Sucrose & Glycerol & $1: 1: 2$ \\
\hline DL-Malic acid & L-Proline & Choline chloride & $1: 1: 1$ \\
\hline Citric acid & D-Xylose & & $1: 1^{\mathrm{a}}$ \\
\hline Citric acid & D-(+)-Glucose & & $2: 1^{\mathrm{a}}$ \\
\hline Citric acid & $\mathrm{D}-(-)$-Fructose & & $1: 1$ \\
\hline Citric acid & Sorbose & & $1: 1^{\mathrm{a}}$ \\
\hline Citric acid & D-Mannose & & $1: 1$ \\
\hline
\end{tabular}


Table 1 (Continued)

\begin{tabular}{|c|c|c|c|}
\hline \multicolumn{3}{|l|}{ Components } & \multirow[t]{2}{*}{ Mole ratio } \\
\hline Component 1 & Component 2 & Component 3 & \\
\hline Citric acid & D-(+)-Galactose & & $1: 1^{\mathrm{a}}$ \\
\hline Citric acid & Sucrose & & $1: 1$ \\
\hline Citric acid & Maltose & & $2: 1$ \\
\hline Citric acid & D-(+)-Trehalose & & $2: 1$ \\
\hline Citric acid & Raffinose & & $3: 1$ \\
\hline Citric acid & D-Sorbitol & & $1: 1$ \\
\hline Citric acid & Ribitol & & $1: 1$ \\
\hline Citric acid & Xylitol & & $1: 1$ \\
\hline Citric acid & Adonitol & & $1: 1$ \\
\hline Citric acid & L-Proline & & $1: 1,1: 2,1: 3$ \\
\hline Citric acid & DL-Malic acid & & $1: 1^{\mathrm{a}}$ \\
\hline Phytic acid sodium & Betaine & & $1: 6$ \\
\hline Phytic acid sodium & DL-Malic acid & & $1: 6$ \\
\hline Phytic acid sodium & Glycerol & & $1: 6$ \\
\hline Phytic acid sodium & L-Proline & & $1: 6$ \\
\hline Phytic acid sodium & D-(+)-Glucose & & $1: 6$ \\
\hline Phytic acid sodium & Choline chloride & & $1: 3$ \\
\hline D/L-Proline & Sucrose & & $2: 1,3: 1$ \\
\hline $\mathrm{D} / \mathrm{L}$-Proline & Sucrose & & $4: 1,1: 1^{\mathrm{a}}$ \\
\hline $\mathrm{D} / \mathrm{L}$-Proline & D-Sorbitol & & $1: 1$ \\
\hline $\mathrm{D} / \mathrm{L}$-Proline & D-(+)-Glucose & & $1: 1,5: 3$ \\
\hline $\mathrm{D} / \mathrm{L}-$ Proline & Lactic acid & & $1: 1$ \\
\hline $\mathrm{D} / \mathrm{L}$-Proline & DL-Malic acid & & $1: 1$ \\
\hline $\mathrm{D} / \mathrm{L}$-Proline & Citric acid & & $1: 1,2: 1$ \\
\hline $\mathrm{D} / \mathrm{L}$-Proline & Malonic acid & & $1: 1^{\mathrm{a}}$ \\
\hline D-Proline & D-(+)-Glucose & & $5: 3$ \\
\hline L-Proline & D-(+)-Glucose & & $5: 3$ \\
\hline L-Serine & DL-Malic acid & & $3: 2,1: 1$ \\
\hline L-Serine & D-(+)-Glucose & & $5: 4^{\mathrm{a}}$ \\
\hline L-Glutamic salt & Sucrose & & $2: 1$ \\
\hline L-Glutamic salt & $\mathrm{D}-(+)$-Glucose & & $1: 1$ \\
\hline D-(+)-Glucose & DL-Malic acid & & $1: 1^{\mathrm{a}}$ \\
\hline D-(+)-Glucose & Citric acid & & $1: 1$ \\
\hline D-(+)-Glucose & L-(+)-Tartaric acid & & $1: 1$ \\
\hline D-(+)-Glucose & D-(-)-Fructose & Sucrose & $1: 1: 1^{\mathrm{a}}$ \\
\hline D-(-)-Fructose & Sucrose & & $1: 1$ \\
\hline$\beta$-Alanine & DL-Malic acid & & $3: 2,1: 1$ \\
\hline$\beta$-Alanine & Citric acid & & $1: 1$ \\
\hline
\end{tabular}

a Not stable; solid precipitate within 7 days.

amines (choline) in water depleted conditions as compared to its normal growing conditions. Also cold resistance might be related to NADES, and in fact the commonly used cryoprotectants for plants, like sugars, sugar alcohols and proline, are all ingredients of NADES. Furthermore, the NADES can also explain the biosynthesis and storage of poorly water soluble compounds since NADES show high solubilizing capacity for those compounds, as shown in the below solubility results. In particular, NADES maybe involved in solubilizing e.g. water insoluble flavonoids in flowers at very high level. NADES in our view function as an alternative liquid phase to water in nature to protect organisms from drought, cold, and to enable the biosynthesis and storage of poorly water-soluble molecules, including high molecular weight molecules.

\subsection{Structures of NADES}

Nuclear magnetic resonance (NMR) spectroscopy was applied to NADES in search for molecular interactions involved in this phenomenon. To start with, the existence of hydrogen bonds in these NADES was observed. Abbott et al. observed a cross-correlation between the fluoride ion from choline fluoride and protons from urea using heteronuclear Overhauser spectroscopy (HOESY) [4]. Also, Mele et al. observed a direct intermolecular and intramolecular interaction between 1- $n$ butyl-3-methylimidazolium tetrafluoroborate molecules through ${ }^{1} \mathrm{H}-{ }^{1} \mathrm{H}$-nuclear overhauser spectroscopy (NOESY) [26]. In our study, for example, the HOESY spectrum of 1,2-propanediolcholine chloride- $\mathrm{H}_{2} \mathrm{O}(\mathrm{PCH})$ revealed a signal corresponding to

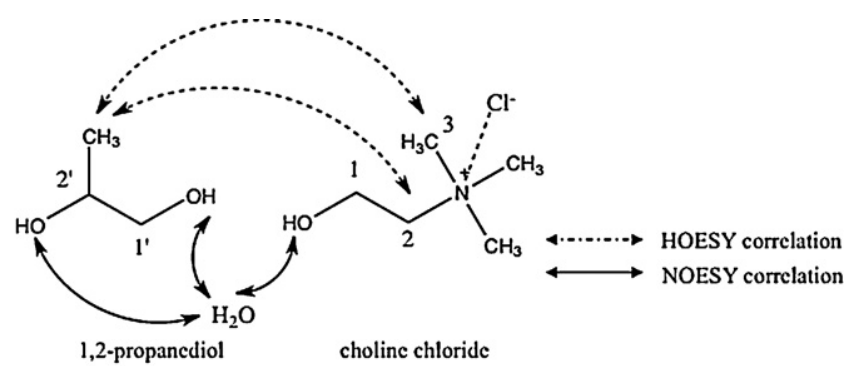

a)
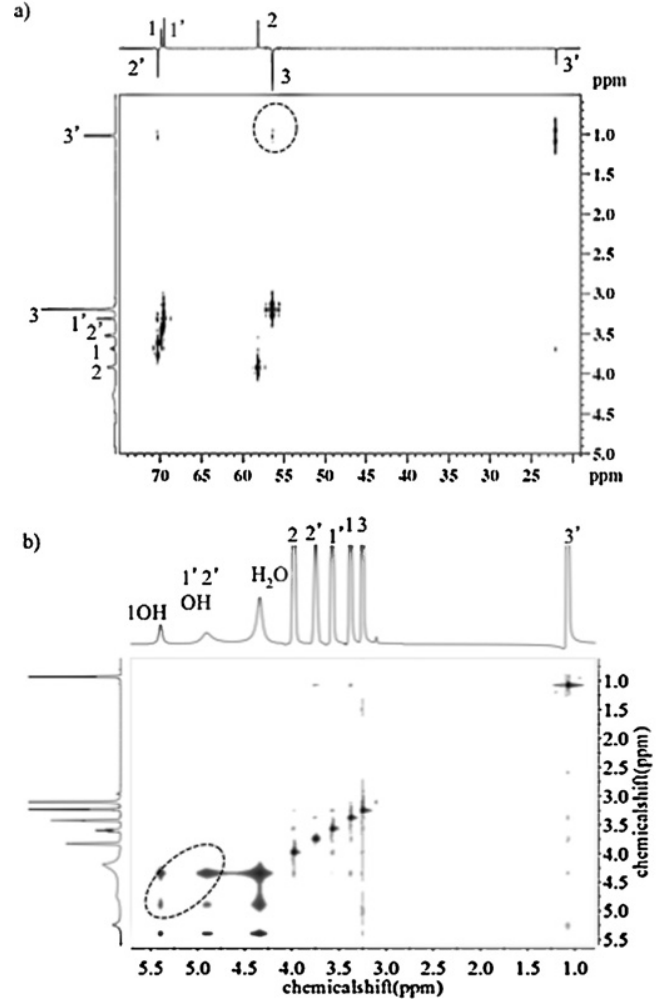

Fig. 1. 2D NMR spectra of 1,2-propanediol-choline chloride-water (1:1:1, molar ratio). (a) Heteronuclear overhauser spectroscopy (HOESY); (b) ${ }^{1} \mathrm{H}-{ }^{1} \mathrm{H}$-nuclear overhauser enhancement spectroscopy (NOESY).

the proton on the methyl group of 1,2-propanediol interacting with both the methyl carbon and methylene (connected to nitrogen) carbon of choline chloride. This implies that the protons of the hydroxyl group of 1,2-propanediol may form a hydrogen bond with choline chloride (Fig. 1a). The NOESY spectrum of $\mathrm{PCH}$ shows strong interaction between the protons on the hydroxyl groups from choline chloride, 1,2-propanediol, and water (Fig. 1b), implying that hydrogen bonds are formed between these hydroxyl groups. This example suggests that water might also participate in the supramolecular structure of NADES. A similar interaction was observed in other combinations, such as proline-malic acid-water (PMH) (Fig. S2).

Different ratios of the components of NADES, may affect stability of NADES in terms of the mixture remaining in the liquid phase for prolonged periods. To test this, the stability of mixtures prepared with different molar ratios of compounds was evaluated. In the case of sugars-choline chloride mixture, for example, glucose: choline chloride, a ratio of $2: 5$ moles is stable, but with $2: 1,1: 1$ or 1:4 mole ratio, a clear liquid can be prepared by mixing, but solid (crystalline) precipitate will gradually appear. Similar cases are listed in Table 1. These observations lead to our conclusion that one chloride ion from choline chloride can form two hydrogen bonds with two hydroxyl groups from sugars, thus behaving similarly as 

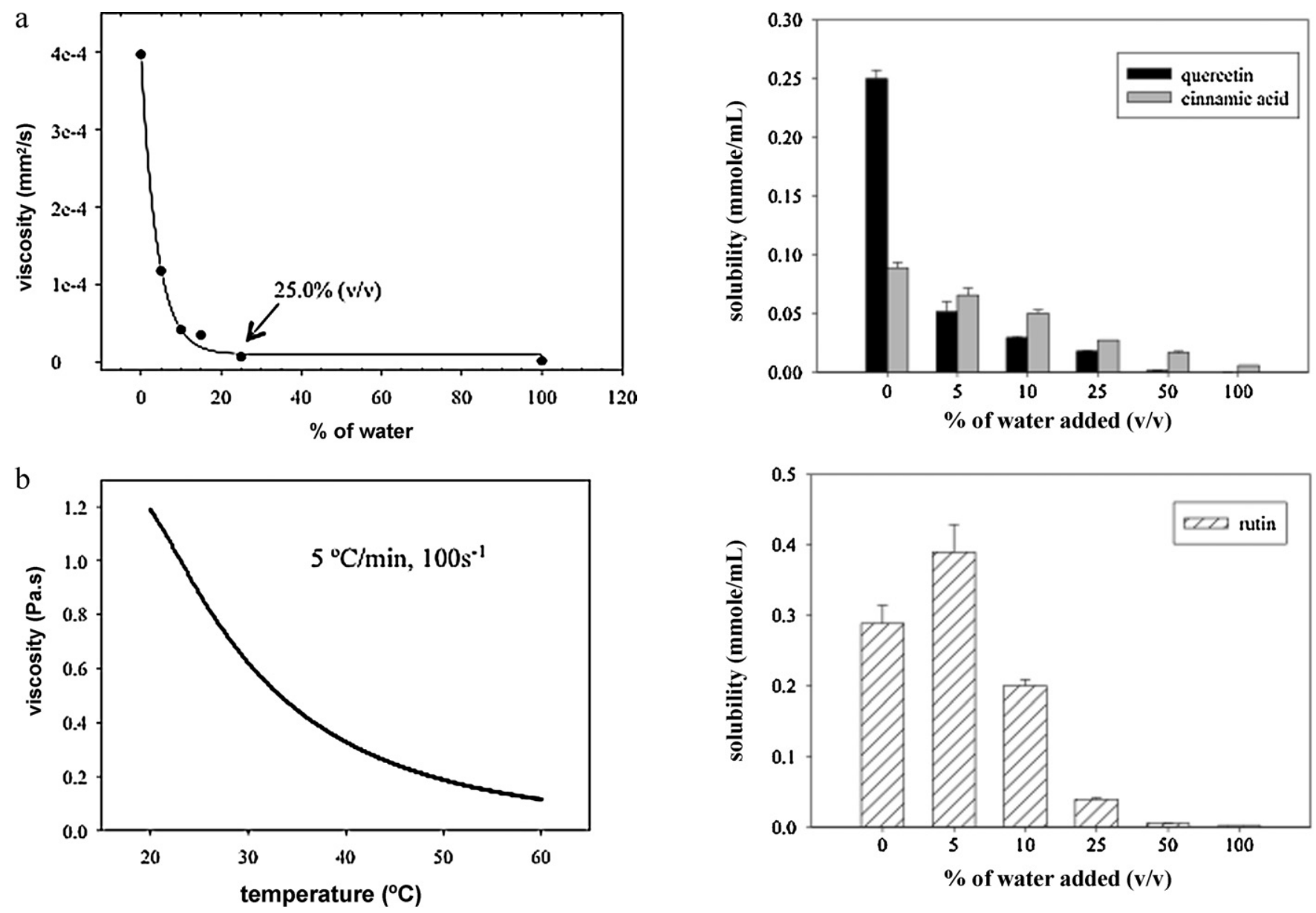

Fig. 2. Relationship between (a) viscosity and added water percentage (v/v), (b) viscosity and temperature of glucose-choline chloride-water (2:5:5, molar ratio).

in a mixture of a choline chloride and a carboxylic acid [5]. A 1:1 molar ratio is suitable for most other combinations. Sugar/sugar alcohol-organic acid/amino acid, amino acid-organic acid, all components are both hydrogen-bond donor and acceptors, which is thought to be the basis for the complexation of the solids yielding liquids with a supramolecular structure. In fact, NADES are like liquid crystals in which all molecules are arranged through hydrogen bonding and other physical intermolecular binding forces.

Another feature to evaluate was the influence of the structure of the compounds on the formation and stability of NADES. To study this, different compounds of similar structures were tested (Table 1). The number of hydrogen bond donor or acceptor groups, the spatial structure of those groups and the position of the bonds appeared to significantly influence the formation and stability of NADES. For example, in the case of organic acids, succinic acid does not form a liquid with choline salts, whereas malic acid, citric acid, and tartaric acid do. Considering the structure of these acids, it is possible to conclude that the presence of extra hydroxyl or carboxyl groups, allows more hydrogen bonds to be formed, thus increasing the stability of the liquids. The same applies for the combinations of organic acids and sugars, those that have more carboxylic groups, such as citric acid, can form stable liquids with more kinds of sugars than those with less carboxylic groups as is the case of malic acid. Not only the number of hydroxyl groups but also their spatial structure has a great influence on the formation and stability of hydrogen bonds. The liquid formed with galactose and choline chloride is not stable and precipitates while the combination of choline chloride with glucose is a stable liquid. A similar phenomenon was

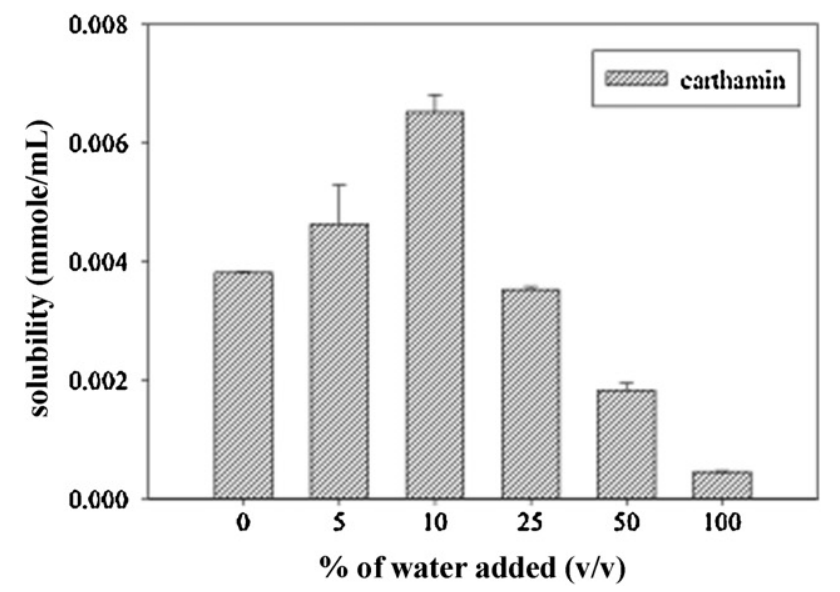

Fig. 3. Solubility of rutin, quercetin, cinnamic acid and carthamin in glucose-choline chloride-water (2:5:5, molar ratio) diluted with different percentage of water.

also observed with other sugars and sugar alcohols, like sorbitol vs mannitol. In the case of disaccharides, trehalose can form a liquid with choline salts or organic acids but cellobiose, which has a different glycosidic bond to trehalose, does not form a liquid.

One of the interesting applications of ILs and DES is their potential use as solvents. The physical properties $[27,28]$ and solubilizing capacity $[29,30]$ of ILs, can be modified by the addition of small quantities of water. In the case of DES, previous studies have reported that most of them were not liquid at room temperature $[4,5,7]$ and consequently there is a limitation for their application to extraction or reaction media at room temperature. In this study we found that small amounts of water (around 5-10\% of water, e.g. 
Table 2

Physical properties of natural ionic liquids or deep eutectic solvents with water and methanol as references.

\begin{tabular}{|c|c|c|c|c|c|c|c|c|}
\hline Name & Composition (mole ratio) & $\begin{array}{l}\text { Water } \\
\text { (wt\%) }\end{array}$ & $\begin{array}{l}\text { Water activity } \\
\left(40^{\circ} \mathrm{C}\right)\end{array}$ & $\begin{array}{l}\text { Density }\left(40^{\circ} \mathrm{C}\right) \\
\left(\mathrm{g} / \mathrm{cm}^{3}\right)\end{array}$ & $\begin{array}{l}\text { Viscosity }\left(40^{\circ} \mathrm{C}\right) \\
\left(\mathrm{mm}^{2} / \mathrm{s}\right)\end{array}$ & $T_{\text {decom }}{ }^{\mathrm{a}}\left({ }^{\circ} \mathrm{C}\right)$ & $T_{\mathrm{g}}{ }^{\mathrm{b}}\left({ }^{\circ} \mathrm{C}\right)$ & $\begin{array}{l}E_{\mathrm{NR}}{ }^{\mathrm{c}} \\
(\mathrm{kcal} / \mathrm{mol})\end{array}$ \\
\hline $\mathrm{MCH}$ & Malic acid:choline chloride:water $(1: 1: 2)$ & 11.62 & 0.195 & 1.2303 & 445.9 & 201 & -71.32 & 44.81 \\
\hline GlyCH & Glycerol:choline chloride:water (2:1:1) & 5.26 & 0.126 & 1.1742 & 51.3 & 187 & -101.59 & 49.55 \\
\hline MAH & Malic acid: $\beta$-alanine:water $(1: 1: 3)$ & 19.48 & 0.573 & 1.352 & 174.6 & 164 & -70.88 & 48.05 \\
\hline $\mathrm{PMH}$ & Proline:malic acid:water $(1: 1: 3)$ & 17.81 & 0.591 & 1.3184 & 251 & 156 & -61.29 & 48.3 \\
\hline $\mathrm{FCH}$ & Fructose:choline chloride:water (2:5:5) & $7.84 \%$ & 0.151 & 1.2078 & 280.8 & 160 & -84.58 & 49.81 \\
\hline $\mathrm{XCH}$ & Xylose:choline chloride:water $(1: 2: 2)$ & 7.74 & 0.141 & 1.2095 & 308.3 & 178 & -81.8 & 49.81 \\
\hline $\mathrm{SCH}$ & Sucrose:choline chloride:water $(1: 4: 4)$ & 7.40 & 0.182 & 1.2269 & 581 & $>200$ & -82.96 & 49.72 \\
\hline FGSH & Fructose:glucose:sucrose:water (1:1:1:11) & 22.0 & 0.662 & 1.3657 & 720 & 138 & -50.77 & 48.21 \\
\hline $\mathrm{GCH}$ & Glucose:choline chloride:water (2:5:5) & 7.84 & 0.162 & 1.2069 & 397.4 & 170 & -83.86 & 49.72 \\
\hline $\mathrm{PCH}$ & 1,2-Propanediol:choline chloride:water (1:1:1) & 7.70 & 0.242 & 1.0833 & 33 & 162 & -109.55 & 50.07 \\
\hline LGH & Lactic acid:glucose:water ( $5: 1: 3)$ & 7.89 & 0.496 & 1.2497 & 37 & 135 & -77.06 & 44.81 \\
\hline $\mathrm{SoCH}$ & Sorbitol:choline chloride:water (2:5:6) & 9.23 & 0.12 & 1.1854 & 138.4 & $>200$ & -89.62 & 49.98 \\
\hline $\mathrm{XoCH}$ & Xylitol:choline chloride:water (1:2:3) & 11.17 & 0.116 & 1.17841 & 86.1 & $>200$ & -93.33 & 49.72 \\
\hline $\mathrm{H}_{2} \mathrm{O}$ & Water & 100 & 1 & 0.992 & $\approx 1$ & - & - & 48.21 \\
\hline $\mathrm{MeOH}$ & Methanol & - & - & 0.791 & - & - & - & 51.89 \\
\hline
\end{tabular}

a Decomposition temperature.

b Glass transition temperature.

${ }^{c} E_{\mathrm{NR}}=h c N_{\mathrm{A}} / \lambda_{\max }=28591 / \lambda_{\max }$.

2:5:5 in molar combinations in case of GCH, Table 2) resulted in a liquid at room temperature and even at lower temperature. This fits in with our hypothesis of the role of NADES in nature as regards to desiccation of various organisms in which NADES are formed after the evaporation of water. However, extension dilution of DES with water will result in the loss of existing hydrogen bonds, and consequently, the disappearance of the special structure of DES [31]. Adding small amount of water to a NADES has other effects such as reducing the preparation time and temperature, and decreasing their viscosity (Fig. 2a). The molar ratio of water that is compatible with the stability of liquid NADES at room temperature is listed in Table 2. The water activity values of most DES are close to 0.2 , much lower than the mole percentage of water in each DES, indicating that the water in NADES is difficult to evaporate as it is in the form of bonded water. Most importantly, the physical properties of NADES, e.g. solubilizing capacity, can be tuned by varying the water content, leading in some cases, to a higher solubility of plant secondary metabolites such as rutin, carthamin and cinnamic acid (Fig. 3).

\subsection{Preparation of NADES}

Two methods have been described for the preparation of DES: freeze-drying [31] and heating a mixture of the solids to around $80^{\circ} \mathrm{C}$ [4]. The NADES evaluated in this study can be obtained by heating with stirring at $50^{\circ} \mathrm{C}$ in $0.5-2 \mathrm{~h}$ due to the addition of a small amount of water. This method is not only cheaper but also safer considering that the components are usually thermally unstable, as is the case of sugars or amino acids. Both vacuum evaporating and heating methods tested in this paper show the same chemical profile for the liquid obtained as shown by the ${ }^{1} \mathrm{H}$ NMR spectra (Fig. S3).

\subsection{Physicochemical properties of NADES}

The thermal behavior of NADES was studied using thermogravimetric analysis (TGA) and differential scanning calorimetry (DSC) (Table 2). The weight loss at $100^{\circ} \mathrm{C}$ indicates that the water content in glucose-choline chloride-water (GCH) is $7.8 \%$, which is consistent with the amount of water added. All the NADES were heated to $100^{\circ} \mathrm{C}$ for $1 \mathrm{~h}$, without any evident decomposition. The NADES made of sugars have a low decomposition temperature ( $\left.T_{\text {decomp }}\right)$ of approximately $135^{\circ} \mathrm{C}$ but others have a $T_{\text {decomp }}$ that is even above $200^{\circ} \mathrm{C}$. All NADES evaluated by DSC revealed that they have glass transition points $\left(T_{\mathrm{g}}\right)$ below $-50^{\circ} \mathrm{C}$ but without a melting point, which confirms that those NADES are supramolecular complexes, with a stable liquid status over a wide temperature range. The liquid state of NADES at low temperature supports our hypothesis that NADES play an important role in plant for cold resistance. Also, it implies that NADES can be used as solvents in a range between at least 0 and $100^{\circ} \mathrm{C}$.

Important physical properties including density, viscosity and polarity were examined (Table 2 ). The densities of all tested NADES proved to be higher than that of water. Viscosity is one of the most important characteristics and also one of the largest obstacles for the application of ILs and DES. The viscosity of NADES is affected by water percentage and temperature. In the case of GCH with different water percentages (v/v) (Fig. 2a), its viscosity decreased by $1 / 3$ when diluted with $5 \%$ water, and decreased to $1 / 10$ of the original value with the addition of $10 \%$ water. The viscosity of GCH decreased by $2 / 3$ when the temperature increased from 20 to $40^{\circ} \mathrm{C}$ (Fig. 2b). Polarity is another important property of NADES, since it affects theirs solubilizing capacity. Organic acidbased NADES are the most polar ( $44.81 \mathrm{kcal} \mathrm{mol}^{-1}$ ), followed by amino acids and pure sugar based NADES with a polarity similar to water $\left(48.21 \mathrm{kcal} \mathrm{mol}^{-1}\right)$. Both sugar and polyalcohol based NADES are the least polar, with a polarity close to that of $\mathrm{MeOH}$ $\left(51.89 \mathrm{kcal} \mathrm{mol}^{-1}\right)$. In addition, polarity of NADES may be affected by the addition of water. The evaluation of the polarity of $\mathrm{PCH}$ and lactic acid-glucose-water (LGH) with different ratios of water (Table S1) showed an obvious change of polarity with the addition of $50 \%(\mathrm{v} / \mathrm{v})$ water indicating that this amount of water provoked a dramatic change in the structure of $\mathrm{PCH}$ and LGH, very likely due to the rupture of hydrogen bonding between the two components. This is in agreement with the results of previously reported dilution experiments of DES made of glycerol-choline chloride and urea-choline chloride [31,32].

\subsection{Solubilizing ability of NADES}

Considering the different polarities of the NADES, it is possible that they act as an alternative media to water in organisms, dissolving non water-soluble metabolites or macromolecules. In particular, many plant secondary metabolites are not soluble in water at all, but are synthesized, stored, and transported in plants. A model experiment was carried out to explore the solubilizing capacity of NADES. For this, the solubility of the nonwater soluble or poorly water soluble natural products rutin, quercetin, cinnamic acid, carthamin, taxol, ginkgolide B, and 1,8dihydroxyanthaquinone in $\mathrm{LGH}, \mathrm{GCH}, \mathrm{PCH}$, and xylitol-choline 
Table 3

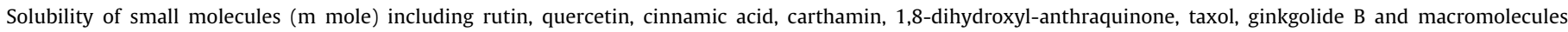
$\left(\mathrm{g} /\right.$ mole $\left._{\text {solvent }}\right)$ including gluten, DNA and starch in different natural deep eutectic solvents or ionic liquids $(n=3)$.

\begin{tabular}{|c|c|c|c|c|c|c|}
\hline & Compounds & $\mathrm{H}_{2} \mathrm{O}$ & $\mathrm{PCH}^{\mathrm{d}}$ & $\mathrm{GCH}^{\mathrm{d}}$ & $\mathrm{LGH}^{\mathrm{d}}$ & $\mathrm{XoCH}^{\mathrm{d}}$ \\
\hline \multirow[t]{7}{*}{ Small molecules } & Rutin $^{\mathrm{a}}$ & 0.01 & 107.09 & 120.6 & 20.36 & 114.15 \\
\hline & Quercetin $^{\mathrm{a}}$ & 0.0004 & 117.60 & 106.19 & 2.57 & 166.95 \\
\hline & Cinnamic acida & 0.13 & 128.47 & 40.54 & 124.6 & 44.29 \\
\hline & Carthamin ${ }^{\mathrm{a}}$ & 0.02 & 4.21 & 2.77 & 0.41 & 6.77 \\
\hline & 1,8-Dihydroxyl anthraquinone ${ }^{a}$ & 0.00 & 0.12 & 0.26 & 0.41 & 0.14 \\
\hline & Taxol $^{\mathrm{a}}$ & 0.0002 & 2.95 & 0.46 & 3.45 & 0.13 \\
\hline & Ginkgolide $B^{a}$ & 0.01 & 38.34 & 6.51 & 2.49 & 11.62 \\
\hline \multirow[t]{3}{*}{ Macromolecules } & Gluten $^{\mathrm{a}}$ & 0.03 & 0.06 & 0.10 & 2.64 & 0.23 \\
\hline & DNA $^{\mathrm{a}}$ & 4.56 & 0.92 & 1.20 & 157.01 & 1.81 \\
\hline & Starch $^{\mathrm{b}}$ & $-c$ & 2.47 & 7.55 & 1.67 & $-c$ \\
\hline
\end{tabular}

a Detection temperature at $40^{\circ} \mathrm{C}$.

b Detection temperature at $100^{\circ} \mathrm{C}$.

c Not detected.

d 1,2-Propanediol-choline chloride-water (PCH), glucose-choline chloride-water (GCH), lactic acid-glucose-water (LGH) and xylitol-choline chloride-water (XoCH).

chloride-water $(\mathrm{XoCH})$ was measured and compared with their solubility in water (Table 3 ). The results indicate that the solubility of most tested compounds was nearly highest in $\mathrm{PCH}$, which is reasonable, considering that $\mathrm{PCH}$ is the least polar. It is noteworthy that the solubility of these compounds increased in NADES by 18-460,000 times compare to water. As a further step, the influence of the water content on the solubilizing capacity of GCH was investigated (Fig. 3). In this case, addition of a small amount of water in $\mathrm{GCH}$ can increase its solubilizing capacity and the optimum water content depended on the compound. For example, rutin showed the highest solubility in $\mathrm{GCH}$ with $5 \%(\mathrm{v} / \mathrm{v})$ water and carthamin was most soluble in $\mathrm{GCH}$ with $10 \%(\mathrm{v} / \mathrm{v})$ water. These results show<smiles>O=c1c(O)c(-c2ccc(O)c(O)c2)oc2cc(O)cc(O)c12</smiles>

quercetin

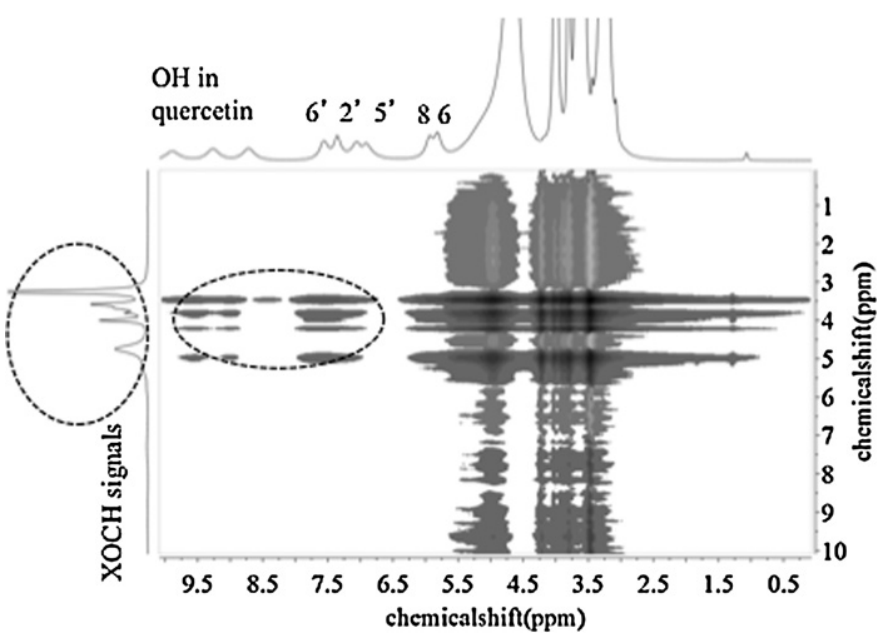

Fig. 4. ${ }^{1} \mathrm{H}-{ }^{1} \mathrm{H}$-nuclear overhauser enhancement spectroscopy of correlation between solute (quercetin) and xylitol-choline chloride-water $(\mathrm{XoCH})(1: 2: 3$, molar ratio) by high-resolution magic angle spinning (HR-MAS) NMR. that water is an important factor in optimizing natural NADES. The solubility of quercetin and carthamin was higher in $\mathrm{XoCH}$ than in $\mathrm{PCH}$. Taxol and 1,8-dihydroxyanthaquinone have the highest solubility in LGH, although LGH is the most polar of the tested NADES. In order to gain more insight into the solubilizing mechanism of NADES, high-resolution magic angle spinning (HR-MAS) NMR was selected to analyze a saturated solution of quercetin in $\mathrm{XoCH}$. Obvious cross peaks between quercetin and $\mathrm{XoCH}$ were observed in the HR-MAS-NOESY spectrum (Fig. 4) indicating that the interaction forces, might result from hydrogen bonding between NADES molecules and solutes, providing an explanation of the high solubilizing capacity of NADES. In addition, the solubility of compounds in NADES affected a lot by temperature. Increasing temperature from 40 to $50^{\circ} \mathrm{C}$, the solubility of quercetin increased to 2.3 times higher in $\mathrm{GCH}$ and 1.65 times higher in PCH (Table S2).

Other usual components of cells are macromolecules such as DNA, proteins, and starch. The solubility of such compounds was also tested in several NADES (Table 3). Starch was found to be more soluble in GCH than $\mathrm{PCH}$, yielding solutions that remained clear at room temperature. On the other hand, gluten and DNA were best soluble in LGH, which is in agreement with their polarity, LGH being the most polar. The solubility in LGH increased 34 times for DNA and 101 times for gluten as compared to that in water. DES made of choline chloride and glycerol has been reported to be a good solvent for DNA, allowing it to keep its native folded structure [33]. This is in agreement with the solubility of DNA in NADES that we observed, a fact that supports the possible importance of NADES in cells.

\section{Conclusions}

This investigation demonstrates that mixtures of many abundant primary metabolites from all kinds of organisms can form natural deep eutectic solvents (NADES) when mixed in adequate ratios. Their NOESY spectra show that they have a supramolecular structure mainly due to hydrogen bonds between the molecules. Also, water can be part of such NADES, and is then strongly bound. Despite high viscosity, the NADES are still liquid at room temperature and even at low temperature. Their viscosity decreases significantly with the addition of small amounts of water, but preserving their characteristics. In addition, they cover a wide range of polarity, from more polar than water to the same as methanol. The NADES proved to be excellent solvents for a wide range of metabolites of low to medium polarity that are non-soluble or poorly soluble in water. Macromolecules such as DNA, proteins and polysaccharides are also soluble in NADES. Their high solubilizing capacity is related to their supramolecular structure and broad polarity range. The existence of NADES in plants and their 
properties indicate that NADES might be involved in the biosynthesis and storage of various non-water soluble metabolites in cells and imply the role of NADES in protecting organisms from extreme conditions. This implies that biosynthesis of poor water-soluble occurs in a NADES in which both substrates and enzymes are dissolved. Consequently, the enzymatic reaction does not occur in water. Thus characteristics of the enzyme might be quite different, e.g. measuring enzyme kinetics with poorly soluble substrates may give erroneous results. Finally, the nontoxic and environmentally friendly NADES makes them fit for numerous various applications in e.g. food, cosmetic, agrochemical and pharmaceutical industry as new Green Technology media.

\section{Acknowledgements}

This work was supported by the Ministry of Land, Transport and Maritime (PM56641), Korea. We thank Ben Norder from Faculty of Mechanical Maritime \& Materials Engineering in Delft University of Technology for DSC, TGA and viscosity tests. Yuntao Dai thanks for the support from PhD program of the China Scholarship Council.

\section{Appendix A. Supplementary data}

Supplementary data associated with this article can be found, in the online version, at http://dx.doi.org/10.1016/j.aca.2012.12.019.

\section{References}

[1] T. Welton, Chem. Rev. 99 (1999) 2071-2083.

[2] A.E. Visser, R.P. Swatloski, R.D. Rogers, Green Chem. 2 (2000) 1-4.

[3] S.Z.E. Abedin, F. Endres, Acc. Chem. Res. 40 (2007) 1106-1113.

[4] A.P. Abbott, G. Capper, D.L. Davies, R.K. Rasheed, V. Tambyrajah, Chem. Commun. 7 (2003) 70-71.

[5] A.P. Abbott, D. Boothby, G. Capper, D.L. Davies, R.K. Rasheed, J. Am. Chem. Soc. 126 (2004) 9142-9147.

[6] J.T. Gorke, F. Srienc, R.J. Kazlauskas, Chem. Commun. 10 (2008) 1235-1237.
[7] G. Imperato, E. Eibler, J. Niedermaier, B. Konig, Chem. Commun. 9 (2005) 1170-1172.

[8] S. Gore, S. Baskaran, B. Koenig, Green Chem. 13 (2011) 1009-1013.

[9] B. Tang, W. Bi, M. Tian, K.H. Row, J. Chromatogr. B 904 (2012) 1-21.

[10] S. Park, R.J. Kazlauskas, Curr. Opin. Biotechnol. 14 (2003) 432-437.

[11] X. Han, D.W. Armstrong, Acc. Chem. Res. 40 (2007) 1079-1086.

[12] R. Liu, J.F. Liu, Y.G. Yin, X.L. Hu, G.B. Jiang, Anal. Bioanal. Chem. 393 (2009) 871-883.

[13] F. Ilgen, B. Konig, Green Chem. 11 (2009) 848-854.

[14] A.P. Abbott, J. Collins, I. Dalrymple, R.C. Harris, R. Mistry, F. Qiu, J. Scheirer, W.R. Wise, Aust. J. Chem. 62 (2009) 341-347.

[15] C.A. Nkuku, R.J. LeSuer, J. Phys. Chem. B 111 (2007) 13271-13277.

[16] M. Figueiredo, C. Gomes, R. Costa, A. Martins, C.M. Pereira, F. Silva, Electrochim. Acta 54 (2009) 2630-2634

[17] H.R. Jhong, D.S.H. Wong, C.C. Wan, Y.Y. Wang, T.C. Wei, Electrochem. Commun. 1 (2009) 209-211.

[18] K.M. Docherty, C.F. Kulpa, Green Chem. 7 (2005) 185-189.

[19] D. Zhao, Y. Liao, Z. Zhang, Clean Soil Air Water 35 (2007) 42-48.

[20] Y. Fukaya, Y. Iizuka, K. Sekikawa, H. Ohno, Green Chem. 9 (2007) 1155-1157.

[21] K. Fukumoto, M. Yoshizawa, H. Ohno, J. Am. Chem. Soc. $127(2005)$ 2398-2399.

[22] L. Poletti, C. Chiappe, L. Lay, D. Pieraccini, L. Polito, G. Russo, Green Chem. 9 (2007) 337-341.

[23] Y.H. Choi, J. van Spronsen, Y. Dai, M. Verberne, F. Hollmann, I.W.C.E. Arends, G.J Witkamp, R. Verpoorte, Plant Physiol. 156 (2011) 1701-1705.

[24] W. Ogihara, T. Aoyama, H. Ohno, Chem. Lett. 33 (2004) 1414-1415.

[25] R.P. Swatloski, S.K. Spear, J.D. Holbrey, R.D. Rogers, J. Am. Chem. Soc. 124 (2002) 4974-4975.

[26] A. Mele, C.D. Tran, S.H. De Paoli Lacerda, Angew. Chem. Int. Ed. Engl. 42 (2003) 4364-4366.

[27] J.A. Widegren, A. Laesecke, J.W. Magee, Chem. Commun. 12 (2005) 1610-1612.

[28] T. Koddermann, C. Wertz, A. Heintz, R. Ludwig, Angew. Chem. Int. Ed. Engl. 45 (2006) 3697-3702.

[29] V. Najdanovic-Visak, J. Esperanca, L.P.N. Rebelo, M.N. da Ponte, H.J.R. Guedes, K.R. Seddon, H.C. de Sousa, J. Szydlowski, J. Phys. Chem. B 107 (2003) 12797-12807.

[30] V. Najdanovic-Visak, L.P.N. Rebelo, M.N. da Ponte, Green Chem. 7 (2005) 443-450.

[31] M.C. Gutiérrez, M.L. Ferrer, C.R. Mateo, F. del Monte, Langmuir 25 (2009) 5509-5515.

[32] M.C. Gutiérrez, M.L. Ferrer, L. Yuste, F. Rojo, F. del Monte, Angew. Chem. Int. Ed. Engl. 49 (2010) 2158-2162.

[33] I. Mamajanov, A.E. Engelhart, H.D. Bean, N.V. Hud, Angew. Chem. Int. Ed. Engl. 49 (2010) 6310-6314. 